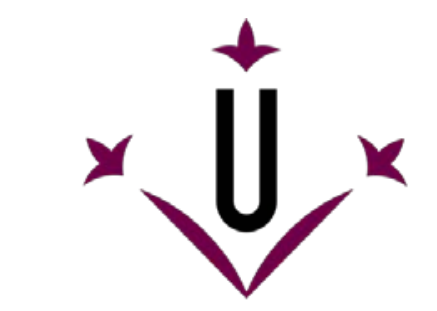

Universitat de Lleida

Document downloaded from:

http://hdl.handle.net/10459.1/65513

The final publication is available at:

https://doi.org/10.1007/s00213-018-4982-9

Copyright

(c) Springer Verlag, 2018 


\section{Palmitoylethanolamide prevents neuroinflammation, reduces astrogliosis and preserves recognition and spatial memory following induction of neonatal anoxia-ischemia}

Mariana I. Holubiec a,1,2, Juan I. Romero a,1,2, Juan Suárez a, Manuel Portavella b, Emilio FernándezEspejo c, Fernando Rodríguez de Fonseca ${ }^{a^{*}}$, Eduardo Blanco ${ }^{\mathrm{d}}$, Pablo Galeano a,2*

a Unidad de Gestión Clínica de Salud Mental, Instituto de Investigación Biomédica de Málaga (IBIMA), Hospital Regional Universitario de Málaga, Avenida Carlos Haya 82, 29010 Málaga, Spain.

b Laboratorio de Conducta Animal y Neurociencia, Departamento de Psicología Experimental, Facultad de Psicología, Universidad de Sevilla, C/Camilo José Cela s/n, 41018 Sevilla, Spain.

c Laboratorio de Neurofisiología y Neurología Molecular, Departamento de Fisiología Médica y Biofísica, Facultad de Medicina, Universidad de Sevilla, Av. Sánchez Pizjuán 4, 41009 Sevilla, Spain. d University of Lleida, Lleida Institute for Biomedical Research, Dr. Pifarré Foundation (IRBLleida), Av. Alcalde Rovira Roure 80, 25198 Lleida, Spain.

${ }^{1}$ These authors contributed equally to this work

${ }^{*}$ Correspondence should be addressed to: Prof. Dr. Fernando Rodríguez de Fonseca, UGC de Salud Mental, Instituto de Investigación Biomédica de Málaga (IBIMA), Hospital Regional Universitario de Málaga, Universidad de Málaga, Avda. Carlos Haya 82, 29010 Málaga, Spain. E-mail address: fernando.rodriguez@ibima.eu, ORCID: 0000-0002-4516-5795; Prof. Dr. Eduardo Blanco, University of Lleida, Lleida Institute for Biomedical Research, Dr. Pifarré Foundation (IRBLleida), Av. Alcalde Rovira Roure 80, 25198 Lleida, Spain. E-mail address: eduardo.blanco@pip.udl.cat, ORCID: 0000-0003-0357-1151; Dr. Pablo Galeano, Instituto de Investigaciones Bioquímicas de Buenos Aires (IIBBA-CONICET), Av. Patricias Argentinas 435, C1405BWE, Ciudad Autónoma de Buenos Aires, Argentina. E-mail address: pgaleano@leloir.org.ar, ORCID: 0000-0003-4491-2039

${ }^{2}$ Permanent address: Instituto de Investigaciones Bioquímicas de Buenos Aires (IIBBA), Consejo Nacional de Investigaciones Científicas y Técnicas (CONICET), Av. Patricias Argentinas 435, C1405BWE, Ciudad Autónoma de Buenos Aires, Argentina. 


\section{Acknowledgments}

This work was supported by grants from Fundació "La Marató de TV3" (386/C/2011), European Regional Development Funds-European Union (ERDF-EU; Subprograma RETICS Red de Trastornos Adictivos RD16/0017/0001), Ministerio de Economía y Competitividad and ISCIII (PI16/01689) to FRF; Own Plan of the Andalucía TECH, International Campus of Excellence (ICE) to PG, and grants to EFE and FRF from Junta de Andalucía, Spain (EFE, group BIO-127; FRF, group BIO-339). JS holds a "Miguel Servet II" research contract from the National System of Health, ISCIII, EU-ERDF (CPII17/00024). Mariana I. Holubiec is a fellowship holder from Agencia Nacional de Promoción Científica y Tecnológica (ANPCyT, Argentina). Eduardo Blanco is an associate professor of the Serra-Hunter Programme from the Catalan Government. Juan I. Romero and Pablo Galeano are research members from Consejo Nacional de Investigaciones Científicas y Técnicas (CONICET, Argentina).

Conflict of interest: None 


\section{Abstract}

Neonatal anoxia-ischemia (Al) particularly affects the central nervous system. Despite the many treatments that have been tested, none of them has proven to be completely successful. Palmitoylethanolamide (PEA) and oleoylethanolamide (OEA) are acylethanolamides that do not bind to $\mathrm{CB} 1$ or $\mathrm{CB} 2$ receptors and thus they do not present cannabinoid activity. These molecules are agonist compounds of peroxisome proliferator-activator receptor alpha (PPARa), which modulates the expression of different genes that are related to glucose and lipid metabolism, inflammation, differentiation and proliferation. In the present study, we analyzed the effects that the administration of PEA or OEA, after a neonatal Al event, has over different areas of the hippocampus. To this end, 7day-old rats were subjected to $\mathrm{Al}$ and then treated with vehicle, OEA (2 or $10 \mathrm{mg} / \mathrm{kg}$ ) or PEA (2 or 10 $\mathrm{mg} / \mathrm{kg}$ ). At 30 days of age, animals were subjected to behavioral tests followed by immunohistochemical studies. Results showed that neonatal Al was associated with decreased locomotion, as well as recognition and spatial memory impairments. Furthermore, these deficits were accompanied with enhanced neuroinflammation and astrogliosis, as well as a decreased PPARa expression. PEA treatment was able to prevent neuroinflammation, reduce astrogliosis and preserve cognitive functions. These results indicate that the acylethanolamide PEA may play an important role in the mechanisms underlying neonatal $\mathrm{Al}$, and it could be a good candidate for further studies regarding neonatal $\mathrm{Al}$ treatments

Keywords: Neonatal anoxia-ischemia; Palmitoylethanolamide; Oleoylethanolamide; Neuroinflammation; Astrogliosis; Memory impairment 


\section{Introduction}

Neonatal hypoxia ischemia $(\mathrm{HI})$ is an event that is usually triggered during birth. Either fetus lung malfunction or modifications in the placental gas exchange can lead to low levels of oxygen (hypoxia or anoxia) or a diminished blood flow (ischemia) in the fetus (Blanco et al. 2015; Carrera 2006). Neonatal HI particularly affects the central nervous system (CNS) (Kumar et al. 2007), which is highly susceptible to oxidative stress, in part due to the elevated concentration of fatty acids present in this tissue (Halliwel, 1992). So far, hypothermia has been the only treatment that was able to consistently prevent the neurological damage and sequels associated to neonatal $\mathrm{HI}$ (Mishima et al. 2004; Sebetseba et al. 2017). Neonatal $\mathrm{HI}$ is associated to learning and memory impairments (Blanco et al. 2015; Galeano et al. 2011, 2015; Takada et al. 2016). Mainly, it has shown to cause several cellular and molecular modifications in the hippocampus, including astrogliosis and focal swelling, among others (Blanco et al. 2015; Saraceno et al. 2010, 2012).

The endogenous cannabinoids system (ECS) includes different enzymes responsible for endocannabinoid synthesis, transport and degradation, as well as endocannabinoids and endocannabinoid receptors (Ueda et al. 2013). The ECS is important for its regulation over different neurological and physiological processes, that include neural development, synaptic plasticity, reward processing, learning processes, neurogenesis and embryonic cell fate in the developing brain, through the activation of cannabinoid receptors 1 (CB1) and 2 (CB2) (Ahmad and Laviolette 2017; Alonso-Alconada et al. 2011; Blanco-Calvo et al. 2014; Serrano et al. 2012; Schoch et al. 2018; Ueda et al. 2013; Zhou et al. 2017).

Endocannabinoids are produced from membrane phospholipids depending on cell demand, and they are soon degraded by the corresponding enzyme. These compounds are divided into two groups of fatty acid derivatives that present specific structures: acylethanolamides (AEs) and monoacylglycerols (MAGs) (Hansen and Diep 2009; Serrano et al. 2012; Ueda et al. 2013). To the date, the further characterized endocannabinoids are arachidonoyethanolamide ( $A E A$, an $A E$ also known as anandamide) and 2-arachidonoyglycerol (2AG, a MAG). AEs are synthesized from glycerophospholipids and degraded by the fatty acid amide hydrolase (FAAH) (Okamoto et al. 2009; Pasquarelli et al. 2015; Ueda et al. 2013). Other ethanolamine and palmitic acid amides such as palmitoylethanolamide (PEA) and oleoylethanolamide (OEA) are AEs that share both biosynthetic and 
degradative pathways with AEA. However, these amides do not bind to CB1 and CB2 and thus they do not present cannabinoid activity (Fu et al. 2003; Scuderi et al. 2011). These molecules have been described as agonist of peroxisome proliferator-activator receptor alpha (PPARa), which is expressed in microvascular, neuronal and glial tissues, and plays a key role in glucose and lipid metabolism, inflammation, differentiation and proliferation (Cristiano et al. 2005; Xu et al. 2006). Furthermore, this receptor has been shown to play a key role as a neuroprotectant in different disorders (Bhateja et al. 2012; Bordet et al. 2006; Moran et al. 2014).

In previous works it has been shown that OEA and PEA present neuroprotective effects in cerebral ischemia (Ahmad et al. 2012; Naccarato et al. 2010; Yang et al. 2015; Zhou et al. 2012). Moreover, former studies from our group have shown diminished PPARa levels in hippocampus and striatum of animals that had been exposed to perinatal asphyxia (Blanco et al. 2015; Holubiec et al. 2017). In the present study we aimed to analyze the effect that the administration of both PEA and OEA, after a neonatal anoxic-ischemic (AI) event, has over different areas of the hippocampus. To this purpose, the expression of different markers (Iba-1, GFAP and PPARa) was studied and an array of behavioral tests was performed.

\section{Materials and methods}

\subsection{Experimental subjects}

Experiments in this study were performed in accordance with the ARRIVE (Animal Research: Reporting of In Vivo Experiments) and following the standards disposed by the European Directive 2010/63/EU and the Spanish Royal Decree 53/2013 on the protection of animals used for research and other scientific purposes. All experiments (including the used of experimental animals) were approved by the ethic committee "Comité de Ética e Investigación Biosanitaria" of the IBIMA and University of Málaga. Female Sprague Dawley pregnant rats were kept in a vivarium under standard controlled conditions (temperature: $21 \pm 2{ }^{\circ} \mathrm{C}$; humidity: $65 \pm 5 \%$; dark/light cycle: $12 \mathrm{~h} / 12 \mathrm{~h}$ ), and were supplied with ad libitum access to food (Purina chow) and tap water. Twenty-one days after the delivery date, pups were removed from their dams and housed in cages of four animals each under the same standard conditions as mentioned for the pregnant animals. Only male pups were selected to perform the present study. 


\subsection{Common carotid artery ligation and anoxia procedures}

The neonatal anoxia-ischemia model that was used in the present study has been already validated (Lopez-Aguilera et al. 2012; Romero et al. 2015, 2017). Dams were monitored daily in order to determine the exact date of birth of the pups. When the animals were 7 days old (P7), males were selected to be subjected to carotid artery ligation. Pups were anesthetized using a mixture of 40 $\mathrm{mg} / \mathrm{kg}$ ketamine and $4 \mathrm{mg} / \mathrm{kg}$ xylazine in order to also produce analgesia. When the animals were ready they were placed in a heated pad to prevent their body temperature from dropping below $37^{\circ} \mathrm{C}$. The area to be operated on was properly disinfected and an incision was made in order to reach the right common carotid artery. When the artery was free of surrounding tissue it was properly ligated using a 6-0 surgical silk thread. After a recovery period the pups were subjected to a $100 \%$ nitrogen environment at $37^{\circ} \mathrm{C}$ for 3 min to induce anoxia. (Al group $\mathrm{n}=41$ ). The control group was also subjected to the surgical procedure; however the artery was exposed but not ligated. These animals were not exposed to the anoxia treatment either (Sham group $=42$ ). The mortality rate of the procedure was about of $5 \%$.

\subsection{PEA and OEA treatments}

An hour after the artery ligation and nitrogen exposure (or sham procedures) were finished pups were injected intraperitoneally (i.p.) with a DMSO solution [vehicle, $n=9$ sham pups (ShamVeh) and 10 Al pups (Al-Veh)], $2 \mathrm{mg} / \mathrm{kg}$ of OEA [ $=7$ sham pups (Sham-O2) and $n=7 \mathrm{Al}$ pups (AlO2)], $10 \mathrm{mg} / \mathrm{kg}$ of OEA [ $\mathrm{n}=9$ sham pups (Sham-O10) and $\mathrm{n}=9$ Al pups (AI-O10)], $2 \mathrm{mg} / \mathrm{kg}$ of PEA [ = 7 sham pups (Sham-P2) and $\mathrm{n}=7$ Al pups (AI-P2)], and $10 \mathrm{mg} / \mathrm{kg}$ of PEA $[\mathrm{n}=9$ sham pups (Sham$\mathrm{P} 10)$ and $\mathrm{n}=9 \mathrm{Al}$ pups (Al-P10)]. Pups were pseudo-randomly assigned to each group and these were composed by pups from at least three different dams. Twenty-three days after the carotid ligation treatment (or sham procedures), animals were subjected to a battery of behavioral tests and then euthanized and brains collected for immunohistochemistry analysis.

\subsection{Behavioral assessment}

When rats were 30 days old 7-10 animals from each of the groups were subjected to a number of behavioral tests (Elevated Plus Maze, Open Field, Object Recognition, Morris Water Maze and Passive Avoidance tests). Every animal was subjected to a period of handling prior the beginning of the behavioral assessment (five minutes per day during three consecutive days). The whole set of 
tests was carried out during the $12 \mathrm{~h}$ of light and soft background noise was provided throughout the

whole process. Training sessions were recorded (JVC Everio GZHD620 camcorder) and analyzed using a computerized video-tracking system (ANY-maze, Stoelting Co., Wood Dale, IL) or with the ethological software J WatcherV1.0.

\subsubsection{Elevated plus maze test}

The elevated plus maze (EPM) test was carried out in a plus shaped device consisting of a central platform $(11 \times 11 \mathrm{~cm})$ and four equally long arms: two open $(50 \times 11 \times 0.25 \mathrm{~cm})$ arms and two arms surrounded by walls $(50 \times 11 \times 40 \mathrm{~cm})$ (Galeano et al. 2015). The device was set $100 \mathrm{~cm}$ above the floor. The apparatus was evenly illuminated with an intensity measured in open arms of 85-90 lux. For each trial the animal was placed in the middle of the device facing one of the open arms. Animals were left to explore the apparatus for $5 \mathrm{~min}$. An entry to an arm was counted when the rat set all four paws into one arm. Total distance covered, number of times the animal entered a closed arm, percentage of open arm entries (open arm entries/total entries $\times 100$ ) and percentage of time spent in open arms (time spent in open arms/300 × 100) were recorded.

\subsubsection{Open field test}

For the open field (OF) test an evenly illuminated black arena was utilized $(60 \times 60 \mathrm{~cm}$ and 40 cm high) (Galeano et al. 2015). In order to delimit the central and most illuminated area (70 lux) of the arena an imaginary square of $30 \times 30 \mathrm{~cm}$ was drawn over the image of the apparatus during the data analysis. Animals were carefully set in the apparatus and left to explore it for $10 \mathrm{~min}$. An animal was considered to be in the central area when its four paws were on the delimited $30 \times 30 \mathrm{~cm}$ square. Distance covered, number of rears, number of entries and time spent into the central area were recorded in two time bins of 5 min each.

\subsubsection{Novel object recognition test}

The novel object recognition test (NORT) was carried out $24 \mathrm{~h}$ following the OF, using the same arena. NORT is a widely employed and validated test to assess recognition memory (Ennaceur 2010; Ennaceur and Delacour 1988). During the test animals were set in the arena where two identical objects were placed. Rats were allowed to explore the apparatus and the objects for 5 min (sample trial). This trail was followed by a period $(1 \mathrm{~h})$ in which animals were returned to their cages. 
Rats were then returned once more to the arena and were presented with one familiar object and a novel one. Animals were given $3 \mathrm{~min}$ to explore the objects and then returned to their cages (retention trial). The apparatus was evenly illuminated at approximately 70 lux and the device and the objects were thoroughly clean between animals. All possible location or object combinations were employed to prevent bias due to a preference for a particular object or specific location. Animals were considered to be exploring an object when their snout was directed towards it at a distance of $2 \mathrm{~cm}$ or less. Discrimination index (d1) and ratio (d2) scores were calculated using the following formulas: $\mathrm{d} 1$ $=\mathrm{tn}-. \mathrm{tf}$, and $\mathrm{d} 2=(\mathrm{tn}-\mathrm{tf}) /(\mathrm{tn}-\mathrm{tf})$, where $\mathrm{tn}$ is the amount of time that rats expend exploring the novel object and tf is the amount of time rats explored the familiar object.

\subsubsection{Morris water maze test}

For the Morris water maze (MWM) a black steel tank (180 cm diameter; $60 \mathrm{~cm}$ deep) filled with water at $22 \pm 1{ }^{\circ} \mathrm{C}$ and a translucent circular platform were used (Galeano et al. 2011, 2015). Different visual cues were located on the walls surrounding the maze and the whole setting was indirectly illuminated. The tank was divided by the operators in four equal quadrants and the platform was set in the middle of one of the quadrants. According to each quadrant, four starting positions were determined. Latency to platform, distance to platform and swim speed were registered during spatial learning training. In the probe trial, the platform was removed and the percentage of time spent in each quadrant and the numbers of crossings over a circular area (with a diameter larger than platform diameter) located on the previous platform position were recorded.

In the cued learning phase, the surrounding visual cues were covered with a black curtain and the platform was set $2 \mathrm{~cm}$ above water level with a flag attached to it. Eight cued learning trails were performed during two day (four each day). The location of the platform and the starting point were modified for each trial. If after $60 \mathrm{~s}$ the animal had not found the platform it was gently guided to it and left there for $15 \mathrm{~s}$. To assess spatial learning and reference memory the black curtain was removed and the visual cues were available while the platform was set under water $(2 \mathrm{~cm}$ below the water surface). The test consisted of four trials each day, performed over the period of 6 days. The animal was released from one of the starting positions and it was left to explore the maze looking for the hidden escape platform (the platform remained in the same location for all the trails). If the animal was unable to find the platform after $60 \mathrm{~s}$ it was guided to it and left there for $15 \mathrm{~s}$. During each trial the 
starting position was changed and the sequence used varied along the 6 days of the test. Reference memory was assessed $24 \mathrm{~h}$ after the last learning trail with a probe trial of $60 \mathrm{~s}$. For this probe trial the animal was released from a novel starting position and the platform was removed from the maze.

\subsubsection{Passive avoidance}

The passive avoidance test was used to assess associative memory (Deacon et al. 2002). The device consisted of a box $(60 \mathrm{~cm} \times 60 \mathrm{~cm} \times 40 \mathrm{~cm})$ divided in two. The resulting compartments were both $30 \mathrm{~cm}$ long and separated by a door that opened sliding into the floor. One of the compartments was made of white plastic and well illuminated. The second compartment was dim and made of dark, electrifiable metal. During the acquisition phase the rat was placed in the light compartment and it was allowed to freely explore de devise. The moment the animal crossed into the black compartment it received a mild foot shock (1.2 mA, $2 \mathrm{~s}$ duration) and it was promptly removed from the device. One hour later, the retention trial took place and the rat was again placed in the white compartment and was left to freely explore the entire apparatus during a maximum of $10 \mathrm{~min}$ (no foot shock was delivered once it entered the dark compartment). The ratio between the latency of the rat to move into the dark compartment in the retention trial (T2) and in the training sessions (T1) was taken as a measure of associative memory retention (T2/T1) (Deacon et al. 2002).

\subsection{Tissue processing}

After the behavioral assessment was finished, 4-5 randomly chosen rats per group were administered with a mixture of $40 \mathrm{mg} / \mathrm{kg}$ ketamine and $4 \mathrm{mg} / \mathrm{kg}$ xylazine and subjected to an intracardiac perfusion, firstly with saline solution ( $0.9 \%$ Sodium Chloride) with $1 \%(\mathrm{v} / \mathrm{v})$ heparin in order to clean the tissues, and finally with cold $4 \%$ formaldehyde solution (freshly made from paraformaldehyde; Sigma-Aldrich, St. Louis, MO, USA). When the tissue was properly fixated the brain was carefully extracted and post fixed in formaldehyde solution for $2 \mathrm{~h}$ at $4{ }^{\circ} \mathrm{C}$. Finally, $40-\mu \mathrm{m}-$ thick coronal sections were obtained from each brain and they were properly stored in a $0.002 \%$ (w/v) $\mathrm{NaN}_{3}$ solution at $4{ }^{\circ} \mathrm{C}$.

\subsection{Immunohistochemical procedures}

The presence of markers related to neuroinflammation, astrogliosis and the expression of PPARa were assessed using immunohistochemistry. For this purpose sections from each group were 
placed in separate wells in a 24 well plate. Samples were washed 5 times for 10 min using $0.1 \mathrm{M}$

phosphate buffer solution with $0.5 \%$ Tween 20 (PBS-T), at room temperature (RT) in order to properly eliminate the formaldehyde that was used as a fixative agent. To block the endogenous peroxidase, sections were incubated with $30 \% \mathrm{H}_{2} \mathrm{O}_{2}$ in PBS during 30 min at RT. Samples were then washed 5 times for 10 min with PBS-T and unspecific antigens were blocked incubating the sections in $4 \%$ BSA (Bovine Serum Albumin), diluted in PBS-T, for $1 \mathrm{~h}$ at RT. Afterwards samples were washed 5 times for 10 min with PBS-T and then incubated with the corresponding primary antibody [rabbit anti-lba-1 (1:1000, Wako, Osaka, Japan; cat. no. 019-19741; mouse anti-GFAP (1:500, G3893, Sigma; rabbit anti-PPARa (1:100, P11120812, Fitzgerald)] over night at $4{ }^{\circ} \mathrm{C}$. The following day samples were washed 5 times for 10 min using PBS-T and subsequently incubated with horseradish-peroxidase (HRP) biotinylated secondary antibody (donkey anti-rabbit IgG, 5356499, GE Healthcare; goat anti-mouse IgG, $125 \mathrm{~K} 6063$, Sigma) for $2 \mathrm{~h}$ at RT. Once the two hours had elapsed, samples were again washed 5 times for 10 min with PBS-T and incubated with ABC (Avidin-Biotin complex) solution (1:1000; ExtrAvidin peroxidase, Sigma, St Louis, MO, USA) for $1 \mathrm{~h}$ in darkness at RT. The ABC solution was washed 5 times for 10 min using PBS-T. Finally the signal was detected using $0.05 \%$ diaminobenzidine (DAB; Sigma) diluted in PBS containing $0.03 \% \mathrm{H}_{2} \mathrm{O}_{2}$. Sections were then washed several times using running water, mounted on slides treated with poly-L-lysine solution (Sigma) and subjected to a process of dehydration (increasing ethanol concentration followed by xylene). Samples were covered with cover slips using Eukitt mounting medium (Kindler GmBH \& Co., Freiburg, Germany). After they were dry, samples were observed using an Olympus BX41 Microscope coupled with an Olympus DP70 digital camera (Olympus, Germany) or an Olympus BX60 microscope coupled to Olympus DP71 digital camera (Olympus, USA). All the photographs were taken under the same conditions of light and brightness/contrast.

\subsection{Immunohistochemical quantification}

Four to seven coronal sections from Bregma levels -3.14 to $-4.30 \mathrm{~mm}$ (dorsal hippocampus) (Paxinos 2007), from each animal, were selected and employed for immunohistochemical analysis. Quantification was carried out using the "Cell counter" plug in tool from Image J software (NIH, USA). Images were changed to binary code and the area of interest delimited. For Iba-1 and GFAP quantification, $0.08 \mathrm{~mm}^{2}$ squares were set and distributed so that each area of the hippocampus studied (CA1, CA3 and DG) was properly represented, while $0.02 \mathrm{~mm}^{2}$ squares were employed in the 
case of PPARa. The number of positive cells was manually determined in each square and averaged

to determine the number of cells per $\mathrm{mm}^{2}$. Quantifications were made by experimenters blinded to treatments.

\subsection{Statistics analysis}

Behavioral and immunohistochemical data were analyzed by one or two-way ANOVA tests, followed by Tukey's post hoc multiple comparison tests. Moreover, one sample t-tests were employed when it was required. A probability equal or less than $5 \%$ was accepted as statistically significant and always two-sided probabilities were reported. Data are expressed as mean \pm SEM.

\section{Results}

\subsection{Neonatal anoxia-ischemia reduces exploratory activity without modifying anxiety-like behaviors in the EPM and OF tests}

\subsubsection{Elevated plus maze test}

When the distance covered was analyzed, a two-way ANOVA test revealed that the main factor Postnatal condition was significant $\left(F_{(1,73)}=40.7, p<0.001\right)$, while neither the main factor Treatment nor the interaction Postnatal condition $x$ Treatment were significant $\left(F_{(4,73)}=1.4, p=\right.$ n.s.; $F_{(4,73)}<1, p$ $=$ n.s.). Similarly, in the case of closed arms entries, the main factor Postnatal condition was significant $\left(F_{(1,73)}=16.2, p<0.001\right)$, while neither the main factor Treatment nor the interaction Postnatal condition $\times$ Treatment were significant $\left(F_{(4,73)}<1, p=\right.$ n.s.; $F_{(4,73)}<1, p=$ n.s. $)$. These results indicate that rats that were subjected to anoxia-ischemia, regardless of the treatment received, covered a significantly lower distance and visited significantly fewer times the closed arms in comparison with sham groups (see Fig. 1A-B). Regarding anxiety-related behaviors, none of the groups differed neither in the percentage of open arms entries nor in the percentage of time in open

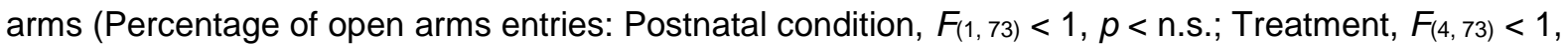
$p=$ n.s.; Postnatal condition $\times$ Treatment, $F_{(4,73)}<1, p=$ n.s. Percentage of time in open arms: Postnatal condition, $F_{(1,73)}<1, p=$ n.s.; Treatment, $F_{(4,73)}<1, p=$ n.s.; Postnatal condition $\mathrm{x}$

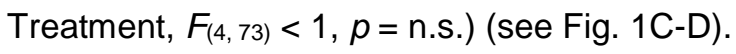

\subsubsection{Open field test}


Two-way mixed ANOVA test revealed that the main factors Group and Time, and the interaction Group x Time were all significant $\left(F_{(9,146)}=4.4, p<0.001 ; F_{(1,146)}=132.4, p<0.001 ; F_{(9 \text {, }}\right.$ 146) $=3.2, p=0.001$, respectively), in the case of distance covered. Post-hoc multiple comparison Tukey tests showed that rats subjected to anoxia-ischemia covered a significantly lower distance than sham groups during the first five minutes (see Fig. 2A). All the groups significantly reduced their distance covered to the same levels during the second five minutes compared with the first five minutes, indicating that every group showed a normal habituation response (see Fig. 2A). When the number of rears was analyzed, the two-way ANOVA tests revealed that the main factors Groups and Time were significant $\left(F_{(9,146)}=2.7, p=0.005 ; F_{(1,146)}=11.2, p=0.001\right.$, respectively), while the interaction Group $x$ Time was not $\left(F_{(9,146)}<1, p=\right.$ n.s. $)$. These results indicate that rats subjected to anoxia-ischemia displayed a significantly lower number of rears across the entire test compared with sham groups and that all groups showed a significantly lower number of rears during the second five minutes than during the first five minutes (see Fig. 2B). Finally, none of the groups presented differecens in anxiety-related behaviors (Entries into the center: Group, $F_{(9,146)}=1.6, p=$ n.s.; Time, $F_{(1,146)}=2.1, p=$ n.s.; Group $\times$ Time, $F_{(9,146)}<1, p=$ n.s. Time in central area: Group, $F_{(9,146)}<1, p=$ n.s.; Time, $F_{(1,146)}=1.1, p=$ n.s.; Group x Time, $F_{(9,146)}<1, p=$ n.s.) (see Fig. $\left.2 C-D\right)$.

\subsection{Palmitoylethanolamide prevents cognitive deficits that follow to neonatal anoxia-ischemia}

\subsubsection{Novel object recognition test}

One-sample t-tests revealed that in groups of rats subjected to anoxia-ischemia, except in the case of Al-P10 group, discrimination index (d1) and discrimination ratio (d2) did not differ from a hypothetical 0 value (d1. Al-Veh: $t=0.4$, d.f. $=8, p=$ n.s.; Al-O2: $t=0.8, d . f .=6, p=$ n.s.; Al-O10: $t=$ 0.6, d.f. $=8, p=$ n.s.; Al-P2: $t=0.5$, d.f. $=6, p=$ n.s. d2. Al-Veh: $t=0.5, d . f .=8, p=$ n.s.; Al-O2: $t=$ 0.6, d.f. $=6, p=$ n.s.; Al-O10: $t=0.4, d . f .=8, p=$ n.s.; Al-P2: $t=0.2$, d.f. $=6, p=$ n.s.) (see Fig. 3A-B). On the other hand, sham groups and the AI-P10 group showed significantly higher $\mathrm{d} 1$ and $\mathrm{d} 2$ than the hypothetical 0 value, meaning that they spent more time exploring the novel object than the familiar one (d1. Sham-Veh: $t=3.5$, d.f. $=9, p=0.006$; Sham-O2: $t=3.3$, d.f. $=6, p=0.013$; Sham-010: $t=$ 3.4, d.f. $=8, p=0.008$; Sham-P2: $t=5.3$, d.f. $=6, p=0.002$; Sham-P10: $t=14.7$, d.f. $=8, p<0.001$; Al-P10: $t=5.0$, d.f. $=8, p=0.002$. d2. Sham-Veh: $t=4.6$, d.f. $=9, p=0.002$; Sham-O2: $t=3.4$, d.f. $=$ $6, p=0.012$; Sham-010: $t=4.2$, d.f. $=8, p=0.002$; Sham-P2: $t=9.7$, d.f. $=6, p<0.001$; Sham-P10: $t$ 
$=9.7$, d.f. $=8, p<0.001 ; \mathrm{Al}-\mathrm{P} 10: t=5.6$, d.f. $=8, p=0.001$ ) (see Fig 3A-B). In this test, treatment with $10 \mathrm{mg} / \mathrm{kg}$ of PEA prevented the recognition memory deficit showed by Al groups.

\subsubsection{MWM test: cue learning}

To analyze the performance of animals during the cue learning phase, the latency to reach the visible platform was used as the dependent variable. Two-way ANOVA test revealed that the main effect of Day was significant $\left(F_{(1,146)}=50.8, p<0.001\right)$, while neither the main effect of Group nor the interaction Day $x$ Group were $\left(F_{(9,146)}<1, p=\right.$ n.s. for both cases) (see Fig. S1). These results mean that all groups significantly reduced their escape latency from one day to another, indicating the absence of visual or motor impairments and a similar level of motivation between the groups to solve the task.

\subsubsection{MWM test: spatial learning and reference memory}

To evaluate spatial memory, the dependent values latency to platform, distance to platform and swim speed were analyzed by two-way ANOVA tests. Results indicated that, in the three cases, the main factor Day was significant (Latency: $F_{(5,438)}=92.4, p<0.001$; Distance: $F_{(5,438)}=115.3, p<$ 0.001; Speed: $\left.F_{(5,438)}=33.5, p<0.001\right)$, while neither the main factor Group nor the interaction Group x Day were significant (Group: Latency, $F_{(9,438)}<1, p=$ n.s.; Distance: $F_{(9,438)}=1.1, p=$ n.s.; Speed, $F_{(9,438)}<1, p=$ n.s. Group x Day: Latency, $F_{(45,438)}<1, p=$ n.s.; Distance: $F_{(45,438)}<1, p=$ n.s.; Speed, $F_{(45,438)}<1, p=$ n.s.). These results show that all groups, regardless of treatment, significantly reduced their latency, distance and swim speeds at the same rate across days of learning (see Fig. $4 A-C)$.

When time spent in the target quadrant (the quadrant where the platform was located during the spatial learning phase) was analyzed during the probe trial, one-sample t-tests revealed that groups of rats subjected to anoxia-ischemia, except the Al-P10 group, spent a not significantly different percentage of time than expected by chance in this area ( $25 \%$, dashed line) (AI-Veh: $t=1.0$, d.f. $=8, p=$ n.s.; Al-O2: $t=1.3$, d.f. $=6, p=$ n.s.; Al-O10: $t=1.6$, d.f. $=8, p=$ n.s.; Al-P2: $t=1.3$, d.f. $=$ $6, p=$ n.s.) (see Fig. 5A). By contrast, sham groups, regardless of treatments, and the AI-P10 group spent significantly higher percentages of time in the target quadrant than expected by chance (ShamVeh: $t=5.8$, d.f. $=9, p<0.001$; Sham-O2: $t=4.2$, d.f. $=6, p=0.005$; Sham-O10: $t=8.8$, d.f. $=8, p<$ 0.001; Sham-P2: $t=5.1$, d.f. $=6, p=0.002$; Sham-P10: $t=8.3$, d.f. $=8, p<0.001$; Al-P10: $t=5.3$, d.f. 
$=8, p<0.001$ ) (see Fig. 5A). A similar pattern of results was obtained when the numbers of crossings over a circular area larger than the platform area were analyzed. The two-way ANOVA test indicated that the main factor Postnatal condition was significant $\left(F_{(1,73)}=29.4, p<0.001\right)$, while neither the main factor Treatment nor the interaction Postnatal condition $\times$ Treatment were significant $\left(F_{(4,73)}=\right.$ 1.9, $p=$ n.s.; $F_{(4,73)}=1.7, p=$ n.s., respectively). Although the interaction Postnatal condition $\mathrm{x}$ Treatment did not reach a significant level, post-hoc multiple comparison Tukey tests showed that groups of rats subjected to ischemia-anoxia crossed the circular area significantly less times compared with sham and Al-P10 groups (see Fig. 5B). These results indicate that anoxia-ischemia was associated with a spatial reference memory deficit that was prevented by the treatment with palmitoylethanolamide at a dose of $10 \mathrm{mg} / \mathrm{kg}$.

\subsubsection{Passive avoidance test}

A two-way ANOVA test to analyze the retention index (T2/T1) showed that neither the main factor Postnatal condition nor the main factor Treatment nor the interaction Postnatal condition $\mathrm{x}$ Treatment were significant $\left(F_{(1,73)}<1, p=\right.$ n.s.; $F_{(4,73)}<1, p=$ n.s.; $F_{(4,73)}<1, p=$ n.s., respectively $)$ (see Fig. S2). This result shows that retention index did not differ among groups, indicating that associative memory was affected neither by anoxia-ischemia nor by treatment with OEA or PEA.

\subsection{Hippocampal neuroinflammation induced by neonatal anoxia-ischemia is prevented by palmitoylethanolamide administration}

When the number of Iba-1 positive cells where analyzed in the CA1 hippocampal area, a twoway ANOVA test revealed that the main factors Postnatal condition (Sham and Al) and Treatment (Veh, O2, O10, P2, P10) and the interaction Postnatal condition $\times$ Treatment were all significant $\left(F_{(1,}\right.$ 33) $=103.9, p<0.001 ; F_{(4,33)}=7.7, p<0.001 ; F_{(4,33)}=3.0, p=0.031$, respectively). Post-hoc multiple comparisons Tukey tests indicated that all groups of rats submitted to neonatal anoxia-ischemia, but the group administered with $10 \mathrm{mg} / \mathrm{kg}$ of PEA, showed a significantly higher number of lba-1 positive cells compared with sham groups (see Fig 6 and Fig. S3). Moreover, Al-P10 group showed a similar number of lba-1 positive cells compared with sham groups (see Fig 6 and Fig. S3). Finally, it was observed that treatment with OEA (2 or $10 \mathrm{mg} / \mathrm{kg}$ ) or PEA (2 or $10 \mathrm{mg} / \mathrm{kg}$ ) had no effect on the number of Iba-1 positive cells among sham groups (see Fig 6 and Fig. S3). 
Similarly to what had been seen in the hippocampal CA1 area, two-way ANOVA tests revealed

that the main factors Postnatal condition and Treatment and the interaction Postnatal condition $\mathrm{x}$ Treatment were all significant when the number of Iba-1 positive cells were analyzed in CA3 and DG areas $\left(\mathrm{CA} 3: F_{(1,33)}=156.0, p<0.001 ; F_{(4,33)}=13.9, p<0.001 ; F_{(4,33)}=3.7, p=0.013\right.$, respectively; DG: $F_{(1,33)}=94.3, p<0.001 ; F_{(4,33)}=11.5, p<0.001 ; F_{(4,33)}=16.9, p<0.001$, respectively). Post-hoc analysis also indicated that, in both hippocampal areas, the number of lba-1 positive cells was significantly higher in the Al groups compared with sham groups, except in the case of the Al-P10 which showed a similar number of Iba-1 positive cells to sham groups (see Fig 6 and Fig. S3). Finally, neither in the CA3 area nor in the DG area, sham groups differed in their number of lba-1 positive cells (see Fig 6 and Fig. S3).

\subsection{Neonatal anoxia-ischemia induces an astrogliosis response that is partially reverted by palmitoylethanolamide treatment}

To analyze the number of GFAP positive cells in the three areas of the hippocampus studied (CA1, CA3 and DG), two-way ANOVA tests were performed and results revealed that the main factor Postnatal condition and the interaction Postnatal condition $\mathrm{x}$ Treatment were both significant (CA1: $F_{(1,33)}=97.3, p<0.001 ; F_{(4,33)}=4.3, p=0.007$, respectively. CA3: $F_{(1,33)}=112.4, p<0.001 ; F_{(4,33)}=$ 3.6, $p=0.014$, respectively. DG: $F_{(1,33)}=69.8, p<0.001 ; F_{(4,33)}=3.1, p=0.029$, respectively). The main factor Treatment was not significant in any of the three hippocampal areas (CA1: $F_{(4,33)}=1.7, p$ $=$ n.s. $\mathrm{CA} 3: F_{(4,33)}=1.0, p=$ n.s. DG: $F_{(4,33)}=1.6, p=$ n.s. $)$.

In the CA1 area, the analyses of simple effects by post-hoc Tukey tests indicated that AI groups, except the AI-P10 group, showed a significantly higher number of GFAP positive cells compared with sham groups (see Fig 7 and Fig. S4). The AI-P10 showed a number of GFAP positive cells that were not significantly different in comparison with sham groups and the AI-P2 group (see Fig 7 and Fig. S4). In the $\mathrm{CA} 3$ area, $\mathrm{Al}-\mathrm{Veh}, \mathrm{Al}-\mathrm{O} 2, \mathrm{Al}-\mathrm{O} 10$ and $\mathrm{Al}-\mathrm{P} 2$ showed a significantly higher number of GFAP positive cells compared to sham group, while AI-P10 showed a significantly higher number of GFAP positive cells in comparison with the Sham-Veh group and significantly lower number compared with Al-Veh and Al-O10 groups (see Fig 7 and Fig. S4) Finally, in the DG, Al groups, except for the Al-P10 group, showed a significantly higher number of GFAP positive cells 
compared with the sham groups, while the AI-P10 group did not significantly differed from the sham

\subsection{Neonatal anoxia-ischemia is associated with a reduced PPARa expression}

Two-way ANOVA tests revealed that the main effect of Postnatal condition was significant in all hippocampal areas when the number of PPARa was analyzed (CA1: $F_{(1,33)}=12.5, p=0.01$. CA3: $F_{(1}$, 33) $=16.5, p<0.001$. DG: $\left.F_{(1,33)}=24.5, p<0.001\right)$, while the main effect of Treatment and the interaction Postnatal condition $\times$ Treatment did not reach significance levels (Treatment: CA1: $F_{(4,33)}=$ 1.2, $p=$ n.s.; CA3: $F_{(4,33)}=1.3, p=$ n.s.; DG: $F_{(4,33)}=2.4, p=$ n.s. Postnatal condition $\times$ Treatment:

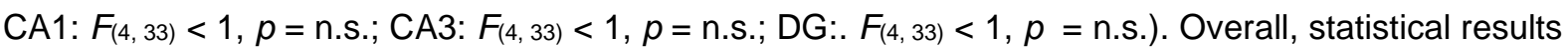
indicate that Al groups, regardless of the treatment received, showed a significantly lower number of PPARa positive cells compared with sham groups (see Fig 8 and Fig. S5).

\section{Discussion}

In the present work we studied the potential neuroprotective effects of PEA and OEA on the hippocampus of animals exposed to neonatal Al. For this purpose, an array of behavioral tests and immunohistochemical analysis were performed. In the EPM and OF tests we were able to observe that animals exposed to Al showed a lower response to novelty, while no changes in anxiety-like behaviors were detected. Furthermore, recognition and spatial reference memory impairments were detected in NORT and MWM tests. These memory deficits were prevented by PEA treatment, while OEA administration had no detectable effects. In addition, neonatal Al was associated with an increased number of Iba-1 and GFAP positive cells in the hippocampus, a critical area for memory processing and especially vulnerable to Al (Dai et al. 2017; Zhu et al. 2018). These neurobiological alterations could be, in part, responsible for the cognitive deficits observed, since PEA treatment was also able to prevent neuroinflammation and reduce astrogliosis. Although the neuroprotective effects of PEA have been studied in animal models of brain injury (Ahmad et al. 2012; D'Agostino et al. 2012; Esposito et al. 2012; Schomacher et al. 2008; Scuderi et al. 2018), as far as we know this is the first time that the neuroprotective properties of PEA are reported in a neonatal model of Al.

\subsection{Neonatal Al is associated with reduced novelty response but not with anxiety-related behaviors}


During the EPM and OF tests we found that animals subjected to Al present a lower number of

entries to the closed arms (locomotion indicator) as well as a decrease in the total distance covered. This effect in locomotion could be attributed to a decrease in the response to novelty since in the OF we only observed this change in locomotion during the first 5 min of the test, while every group presented a normal response to habituation. We, as well as others, have already observed this lower curiosity/motivation to explore novel environments in another model of hypoxia-ischemia (Galeano et al. 2011; Strackx et al. 2010), which suggests that this effect could be related to underlying brain processes altered by oxygen deprivation rather than other mechanisms triggered by a specific animal model.

It is important to note that, unlike other authors (Ming-Yan et al. 2012; Sedláčková et al. 2014), we did not find changes in anxiety-related behaviors. However, this is consistent with previous results from our group in another model of global hypoxia-ischemia (Galeano et al. 2011). We could then hypothesize that these discrepancies may be related to intrinsic differences between animal models of neonatal ischemia. Since the model employed in the present work has been recently validated, effects such as this should be noted for further studies.

\subsection{PEA treatment prevents memory impairments induced by neonatal Al}

Animals exposed to Al showed recognition and spatial reference memory impairments, while associative memory was altered neither by Al nor by pharmacological treatments. Previous works have already found an association between alterations in both NORT and MWM tests and AI (Almli et al. 2000; Barros et al. 2009; Balduini et al. 2000; Cechetti et al. 2010; Cunha-Rodrigues et al. 2018; Domnick et al. 2015; Griva et al. 2017; Pereira et al. 2007). For example, Cunha-Rodrigues et al. (2018) found that pups whose mothers had been subjected to uterine artery ligation showed a recognition memory deficit concomitant with loss of hippocampal neurons. Moreover, Domnick et al. (2015) observed similar results in 2-day-old rat pups subjected to common carotid artery ligation. Regarding spatial memory, Griva et al. (2017) observed that animals subjected to left common carotid artery ligation followed by 60 min of hypoxia $\left(8 \% \mathrm{O}_{2}\right)$ showed an impaired performance in the MWM. Similarly, Cechetti et al. (2010) had already found that animals exposed to bilateral occlusion of the common carotid arteries (2VO) present deficits in spatial memory. In the present work, we were able to observe that treatment with $10 \mathrm{mg} / \mathrm{kg}$ of PEA, administered one hour after $\mathrm{Al}$, prevented 
recognition and reference memory deficits. So far, exogenous administration of PEA has shown to be capable of preventing memory deficits in animal models of Alzheimer's disease (D'Agostino et al. 2012; Scuderi et al. 2014, 2018). Regarding associative memory, similarly to what was reported by Balduini et al. (2000), we did not observe differences between sham and Al groups, suggesting that Al has no effects on this type of memory. This results extent the previously observed neurobehavioral beneficial effects of PEA to an ischemia model, and suggest that PEA could be used as a potential treatment against memory impairments induced by different types of brain injuries.

\subsection{Neuroinflammation and astrogliosis induced by $A l$ is partially prevented by PEA treatment}

In the present work we observed a decrease in PPARa levels in animals subjected to Al, which is consistent with previous results from our group (Blanco et al. 2015; Holubiec et al. 2017). Furthermore, the results obtained in the present study show that there is an increase in neuroinflammation (lba-1) and astrogliosis (GFAP) in animals subjected to Al.

It has already been shown that Al leads to inflammation in different parts of the CNS (Driscoll et al. 2018). During recent years the role that microglia plays in disorders of the CNS has been thoroughly studied (Crews et al. 2017; Salter and Stevens 2017). Microglia has been shown to be involved in different processes such as regulation of embryonic vasculogenesis, secretion of trophic factors, immuno-surveillance, oligodendrogenesis and neurogenesis (Mallard et al. 2018). It has been observed that neuroinflamation due to hypoxia-ischemia plays a key and deleterious role in this event (Galinsky et al. 2018). The production of different factors such as IL-18, Caspase-1 and TGF- $\beta$ has been proven to be related to damages caused by microglia in animals exposed to $\mathrm{Al}$ (Chen et al. 2018; Mallard et al. 2018). Cunha-Rodrigues et al. (2018) has described oligodendrocyte loss, astrogliosis and neuronal death due to $\mathrm{HI}$. It has also been shown that animals subjected to hypoxemia present astrogliosis 6 months post-injury (Davies et al. 2018). Furthermore, it has been previously observed that neuroinflamation and astrogliosis hold a close relation to deficits in recognition memory (Cunha-Rodrigues et al. 2018; Liaury et al. 2014) and spatial memory (Mirahmadi et al. 2017; Pei and Sun 2018). Liaury et al. (2014) has found that microglial activation correlates with schizophrenia-like behaviors. Thus, we propose that the neuroinflamation and astrogliosis that we observed after Al could be resposable, in part, of the memory deficits that followed Al. 
Regarding the treatment with PEA, it has already been demonstrated that this ethanolamide

reduces neuroinflamation and presents a neuroprotective activity in rodents (Di Marzo and Skaper 2013; Petrosino and Di Marzo 2017; Sayd et al. 2014; Scuderi et al. 2014). For instance, in a rat model of Alzheimer's disease induced by the administration of intrahippocampal beta amyloid 1-42, a later treatment with PEA proved to be effective reducing neuroinflamation and exerting neuroprotective actions (Scuderi et al. 2014). Furthermore, PEA was shown to promote neuronal survival in the hippocampus, normalize astrocytic function and balance glutamatergic transmission, thus leading to an improvement in memory impairments (Scuderi et al. 2018). In the present study we show that the increase in neuroinflammation and astroglyosis were partially reverted in animals treated with $10 \mathrm{mg} / \mathrm{kg}$ of PEA. Since PEA also showed a preventive effect regarding the memory deficits observed, we propose that these two phenomena may be closely related.

\section{Conclusions}

In the present work we show that $\mathrm{Al}$ is associated with recognition and spatial memory impairments in a new model of neonatal Al. We have also found that these memory deficits may be related to neuroinflammation and astrogliosis in the hippocampus, since PEA treament partially reversed this alterations and it was able to prevent memory impairments. Although PEA has shown to posses neuroprotective effects in different types of brain injuries, as far as we know this is the first time that these neuroprotetive effects of PEA are observed in a neonatal Al model. Overall, these results indicate that PEA could be a good candidate to focus on in further studies related to $\mathrm{Al}$, a traumantic and not so uncommon event for which effective treatments are lacking. 


\section{References}

Ahmad A, Genovese T, Impellizzeri D, Crupi R, Velardi E, Marino A, Esposito E, Cuzzocrea S (2012) Reduction of ischemic brain injury by administration of palmitoylethanolamide after transient middle cerebral artery occlusion in rats. Brain Res 1477:45-58. https://doi.org/10.1016/j.brainres.2012.08.006 Ahmad T, Laviolette SR (2017) Cannabinoid reward and aversion effects in the posterior ventral tegmental area are mediated through dissociable opiate receptor subtypes and separate amygdalar and accumbal dopamine receptor substrates. Psychopharmacology (Berl) 234:2325-2336. https://doi.org/10.1007/s00213-017-4669-7

Almli CR, Levy TJ, Han BH, Shah AR, Gidday JM, Holtzman DM (2000) BDNF protects against spatial memory deficits following neonatal hypoxia-ischemia. Exp Neurol 166:99-114. https://doi.org/10.1006/exnr.2000.7492

Alonso-Alconada D, Alvarez A, Hilario E (2011) Cannabinoid as a neuroprotective strategy in perinatal hypoxic-ischemic injury. Neurosci Bull 27:275-285. https://doi.org/10.1007/s12264-011$1008-6$

Balduini W, De Angelis V, Mazzoni E, Cimino M (2000) Long-lasting behavioral alterations following a hypoxic/ischemic brain injury in neonatal rats. Brain Res 859:318-325. https://doi.org/10.1016/S00068993(00)01997-1

Barros CA, Ekuni R, Moro MA, Pereira FM, Dos Santos Pereira MA, Milani H (2009) The cognitive and histopathological effects of chronic 4-vessel occlusion in rats depend on the set of vessels occluded and the age of the animals. Behav Brain Res 197:378-387. https://doi.org/10.1016/j.bbr.2008.10.023

Bhateja DK, Dhull DK, Gill A, Sidhu A, Sharma S, Reddy BV, Padi SS (2012) Peroxisome proliferatoractivated receptor- $\alpha$ activation attenuates 3-nitropropionic acid induced behavioral and biochemical alterations in rats: possible neuroprotective mechanisms. Eur $\mathrm{J}$ Pharmacol 674:33-43. https://doi.org/10.1016/j.ejphar.2011.10.029

Blanco E, Galeano P, Holubiec MI, Romero JI, Logica T, Rivera P, Pavón FJ, Suarez J, Capani F, Rodríguez de Fonseca F (2015) Perinatal asphyxia results in altered expression of the hippocampal 
acylethanolamide/endocannabinoid signaling system associated to memory impairments in postweaned rats. Front Neuroanat 9:141. https://doi.org/10.3389/fnana.2015.00141

Blanco-Calvo E, Rivera P, Arrabal S, Vargas A, Pavón FJ, Serrano A, Castilla-Ortega E, Galeano P, Rubio L, Suárez J, Rodriguez de Fonseca F (2014) Pharmacological blockade of either cannabinoid CB1 or CB2 receptors prevents both cocaine-induced conditioned locomotion and cocaine-induced reduction of cell proliferation in the hippocampus of adult male rat. Front Integr Neurosci 7:106. https://doi.org/10.3389/fnint.2013.00106

Bordet R, Ouk T, Petrault O, Gelé P, Gautier S, Laprais M, Deplanque D, Duriez P, Staels B, Fruchart JC, Bastide M (2006) PPAR: a new pharmacological target for neuroprotection in stroke and neurodegenerative diseases. Biochem Soc Trans 34:1341-1346. https://doi.org/10.1042/BST0341341

Carrera JM (2006) Protocolos de Obstetricia y Medicina Perinatal del Instituto Dexeus. Elsevier Masson, Barcelona

Cechetti F, Worm PV, Pereira LO, Siqueira IR, A Netto C (2010) The modified 2 VO ischemia protocol causes cognitive impairment similar to that induced by the standard method, but with a better survival rate. Braz. J Med Biol Res 43:1178-1183. https://doi.org/10.1590/S0100-879X2010007500124

Chen D, Dixon BJ, Doycheva DM, Li B, Zhang Y, Hu Q, He Y, Guo Z, Nowrangi D, Flores J, Filippov V, Zhang JH, Tang J (2018) IRE1 $\alpha$ inhibition decreased TXNIP/NLRP3 inflammasome activation through miR-17-5p after neonatal hypoxic-ischemic brain injury in rats. J Neuroinflammation 15:32. https://doi.org/10.1186/s12974-018-1077-9.

Crews FT, Walter TJ, Coleman LG Jr, Vetreno RP (2017) Toll-like receptor signaling and stages of addiction. Psychopharmacology (Berl) 234:1483-1498. https://doi.org/10.1007/s00213-017-4560-6

Cristiano L, Cimini A, Moreno S, Ragnelli AM, Paola Cerù M (2005). Peroxisome proliferator-activated receptors (PPARs) and related transcription factors in differentiating astrocyte cultures. Neuroscience 131:577-587. https://doi.org/10.1016/j.neuroscience.2004.11.008

Cunha-Rodrigues MC, Balduci CTDN, Tenório F, Barradas PC (2018) GABA function may be related to the impairment of learning and memory caused by systemic prenatal hypoxia-ischemia. Neurobiol Learn Mem 149:20-27. https://doi.org/10.1016/j.nIm.2018.01.004 
D'Agostino G, Russo R, Avagliano C, Cristiano C, Meli R, Calignano A (2012) Palmitoylethanolamide protects against the amyloid- $\beta 25-35$-induced learning and memory impairment in mice, an experimental model of Alzheimer disease. Neuropsychopharmacology 37:1784-1792. https://doi.org/10.1038/npp.2012.25

Dai C, Liu Y, Dong Z (2017) Tanshinone I alleviates motor and cognitive impairments via suppressing oxidative stress in the neonatal rats after hypoxic-ischemic brain damage. Mol Brain 10:52. https://doi.org/10.1186/s13041-017-0332-9

Davies M, Jacobs A, Brody DL, Friess SH (2018) Delayed hypoxemia after traumatic brain injury exacerbates long-term behavioral deficits. J Neurotrauma 35:790-801. https://doi.org/10.1089/neu.2017.5354

Deacon RM, Bannerman DM, Kirby BP, Croucher A, Rawlins JN (2002) Effects of cytotoxic hippocampal lesions in mice on a cognitive test battery. Behav Brain Res 133:57-68. https://doi.org/10.1016/S0166-4328(01)00451-X

Di Marzo V, Skaper SD (2013) Palmitoylethanolamide: biochemistry, pharmacology and therapeutic use of a pleiotropic anti-inflammatory lipid mediator. CNS Neurol Disord Drug Targets 12:4-6. https://doi.org/10.2174/1871527311312010004

Domnick NK, Gretenkord S, De Feo V, Sedlacik J, Brockmann MD, Hanganu-Opatz IL (2015) Neonatal hypoxia-ischemia impairs juvenile recognition memory by disrupting the maturation of $\begin{array}{llll}\text { prefrontal-hippocampal 273:202-214. } & \text { Exporks. }\end{array}$ https://doi.org/10.1016/j.expneurol.2015.08.017

Driscoll DJO, Felice VD, Kenny LC, Boylan GB, O'Keeffe GW (2018) Mild prenatal hypoxia-ischemia leads to social deficits and central and peripheral inflammation in exposed offspring. Brain Behav Immun, in press. https://doi.org/10.1016/j.bbi.2018.01.001

Ennaceur A (2010) One-trial object recognition in rats and mice: methodological and theoretical issues. Behav Brain Res 215:244-254. https://doi.org/10.1016/j.bbr.2009.12.036

Ennaceur A, Delacour J (1988) A new one-trial test for neurobiological studies of memory in rats. 1: behavioral data. Behav Brain Res 31:47-59. https://doi.org/10.1016/0166-4328(88)90157-X 
Esposito E, Impellizzeri D, Mazzon E, Paterniti I, Cuzzocrea S (2012) Neuroprotective activities of palmitoylethanolamide in an animal model of Parkinson's disease. PLoS One 7:e41880. https://doi.org/10.1371/journal.pone.0041880

Fu J, Gaetani S, Oveisi F, Lo Verme J, Serrano A, Rodríguez De Fonseca F, Rosengarth A, Luecke H, Di Giacomo B, Tarzia G, Piomelli D (2003) Oleylethanolamide regulates feeding and body weight through activation of the nuclear receptor PPAR-alpha. Nature 425:90-93. https://doi.org/10.1038/nature01921

Galeano P, Blanco E, Logica Tornatore TM, Romero JI, Holubiec MI, Rodríguez de Fonseca F, Capani F (2015) Life-long environmental enrichment counteracts spatial learning, reference and working memory deficits in middle-aged rats subjected to perinatal asphyxia. Front Behav Neurosci 8:406. https://doi.org/10.3389/fnbeh.2014.00406

Galeano P, Blanco Calvo E, Madureira de Oliveira D, Cuenya L, Kamenetzky GV, Mustaca AE, Barreto GE, Giraldez-Alvarez LD, Milei J, Capani F (2011) Long-lasting effects of perinatal asphyxia on exploration, memory and incentive downshift. Int $J$ Dev Neurosci 29:609-619. https://doi.org/10.1016/j.ijdevneu.2011.05.002

Galinsky R, Lear CA, Dean JM, Wassink G, Dhillon SK, Fraser M, Davidson JO, Bennet L, Gunn AJ (2018) Complex interactions between hypoxia-ischemia and inflammation in preterm brain injury. Dev Med Child Neurol 60:126-133. https://doi.org/10.1111/dmcn.13629

Griva M, Lagoudaki R, Touloumi O, Nousiopoulou E, Karalis F, Georgiou T, Kokaraki G, Simeonidou C, Tata DA, Spandou E (2017) Long-term effects of enriched environment following neonatal hypoxiaischemia on behavior, BDNF and synaptophysin levels in rat hippocampus: effect of combined treatment with G-CSF. Brain Res 1667:55-67. https://doi.org/10.1016/j.brainres.2017.05.004

Halliwell B (1992) Reactive oxygen species and the central nervous system. J Neurochem 59:16091623. https://doi.org/10.1111/j.1471-4159.1992.tb10990.x

Hansen HS, Diep TA (2009) N-acylethanolamines, anandamide and food intake. Biochem Pharmacol 78:553-560. https://doi.org/10.1016/j.bcp.2009.04.024

Holubiec MI, Romero JI, Blanco E, Tornatore TL, Suarez J, Rodríguez de Fonseca F, Galeano P, Capani $F$ (2017) Acylethanolamides and endocannabinoid signaling system in dorsal striatum of rats 
exposed to perinatal asphyxia. Neurosci Lett https://doi.org/10.1016/j.neulet.2017.05.06828579484

Kumar A, Gupta A, Talukdar B (2007) Clinico-etiological and EEG profile of neonatal seizures. Indian J Pediatr 74:33-37. https://doi.org/10.1007/s12098-007-0023-0

Liaury K, Miyaoka T, Tsumori T, Furuya M, Hashioka S, Wake R, Tsuchie K, Fukushima M, Limoa E, Tanra AJ, Horiguchi J (2014) Minocycline improves recognition memory and attenuates microglial activation in Gunn rat: a possible hyperbilirubinemia-induced animal model of schizophrenia. Prog Neuropsychopharmacol Biol Psychiatry 50:184-190. https://doi.org/10.1016/j.pnpbp.2013.12.017

López-Aguilera F, Plateo-Pignatari MG, Biaggio V, Ayala C, Seltzer AM (2012) Hypoxic preconditioning induces an AT2-R/VEGFR-2(Flk-1) interaction in the neonatal brain microvasculature for neuroprotection. Neuroscience 216:1-9. https://doi.org/10.1016/j.neuroscience.2012.04.070

Mallard C, Tremblay ME, Vexler ZS (2018) Microglia and neonatal brain injury. Neuroscience, in press. https://doi.org/10.1016/j.neuroscience.2018.01.023

Ming-Yan H, Luo YL, Zhang XC, Liu H, Gao R, Wu JJ (2012) Hypoxic-ischemic injury decreases anxiety-like behavior in rats when associated with loss of tyrosine-hydroxylase immunoreactive neurons of the substantia nigra. Braz J Med Biol Res 45:13-19. https://doi.org/10.1590/S0100879X2011007500161

Mirahmadi SM, Shahmohammadi A, Rousta AM, Azadi MR, Fahanik-Babaei J, Baluchnejadmojarad T, Roghani M (2017) Soy isoflavone genistein attenuates lipopolysaccharide-induced cognitive impairments in the rat via exerting anti-oxidative and anti-inflammatory effects. Cytokine, in press. https://doi.org/10.1016/j.cyto.2017.10.008

Mishima K, Ikeda T, Yoshikawa T, Aoo N, Egashira N, Xia YX, Ikenoue T, Iwasaki K, Fujiwara M (2004) Effects of hypothermia and hyperthermia on attentional and spatial learning deficits following neonatal hypoxia-ischemic insult in rats. Behav Brain Res 151:209-217. https://doi.org/10.1016/j.bbr.2003.08.018

Moran E, Ding L, Wang Z, Cheng R, Chen Q, Moore R, Takahashi Y, Ma JX (2014) Protective and antioxidant effects of PPARa in the ischemic retina. Invest Ophthalmol Vis Sci $55: 4568-4576$. https://doi.org/10.1167/iovs.13-13127 
Naccarato M, Pizzuti D, Petrosino S, Simonetto M, Ferigo L, Grandi FC, Pizzolato G, Di Marzo V (2010) Possible anandamide and palmitoylethanolamide involvement in human stroke. Lipids Health Dis 9:47. https://doi.org/10.1186/1476-511X-9-47

Okamoto Y, Tsuboi K, Ueda N (2009) Enzymatic formation of anandamide. Vitam Horm 81:1-24. https://doi.org/10.1016/S0083-6729(09)81001-7

Pasquarelli N, Porazik C, Hanselmann J, Weydt P, Ferger B, Witting A (2015) Comparative biochemical characterization of the monoacylglycerol lipase inhibitor KML29 in brain, spinal cord, liver, spleen, fat and muscle tissue. Neuropharmacology 91:148-156. https://doi.org/10.1016/j.neuropharm.2014.12.001

Paxinos G, Whatson C (2007) The Rat Brain in Stereotaxic Coordinates. Elsevier, Amsterdam

Pei B, Sun J (2018) Pinocembrin alleviates cognition deficits by inhibiting inflammation in diabetic mice. J Neuroimmunol 314:42-49. https://doi.org/10.1016/j.jneuroim.2017.11.006

Pereira LO, Arteni NS, Petersen RC, da Rocha AP, Achaval M, Netto CA (2007) Effects of daily environmental enrichment on memory deficits and brain injury following neonatal hypoxia-ischemia in the rat. Neurobiol Learn Mem 87:101-108. https://doi.org/10.1016/j.nIm.2006.07.003

Petrosino S, Di Marzo V (2017) The pharmacology of palmitoylethanolamide and first data on the therapeutic efficacy of some of its new formulations. $\mathrm{Br} J$ Pharmacol 174:1349-1365. https://doi.org/10.1111/bph.13580

Romero JI, Hanschmann EM, Gellert M, Eitner S, Holubiec MI, Blanco-Calvo E, Lillig CH, Capani F (2015) Thioredoxin 1 and glutaredoxin 2 contribute to maintain the phenotype and integrity of neurons following perinatal asphyxia. Biochim Biophys Acta 1850:1274-1285. https://doi.org/10.1016/j.bbagen.2015.02.015

Romero JI, Holubiec MI, Tornatore TL, Rivière S, Hanschmann EM, Kölliker-Frers RA, Tau J, Blanco E, Galeano P, Rodríguez de Fonseca F, Lillig CH, Capani F (2017) Neuronal damage induced by perinatal asphyxia is attenuated by postinjury glutaredoxin-2 administration. Oxid Med Cell Longev 2017:4162465. https://doi.org/10.1155/2017/4162465 
Salter MW, Stevens B (2017) Microglia emerge as central players in brain disease. Nat Med 23:10181027. https://doi.org/10.1038/nm.4397

Saraceno GE, Bertolino ML, Galeano P, Romero JI, Garcia-Segura LM, Capani F (2010) Estradiol therapy in adulthood reverses glial and neuronal alterations caused by perinatal asphyxia. Exp Neurol 223:615-622. https://doi.org/10.1016/j.expneurol.2010.02.010

Saraceno GE, Castilla R, Barreto GE, Gonzalez J, Kölliker-Frers RA, Capani F (2012) Hippocampal dendritic spines modifications induced by perinatal asphyxia. Neural Plast 2012:873532. https://doi.org/10.1155/2012/873532

Sayd A, Antón M, Alén F, Caso JR, Pavón J, Leza JC, Rodríguez de Fonseca F, García-Bueno B, Orio L (2014) Systemic administration of oleoylethanolamide protects from neuroinflammation and anhedonia induced by LPS in rats. Int $\mathrm{J}$ Neuropsychopharmacol 18:pyu111. https://doi.org/10.1093/ijnp/pyu111

Schoch H, Huerta MY, Ruiz CM, Farrell MR, Jung KM, Huang JJ, Campbell RR, Piomelli D, Mahler SV (2018) Adolescent cannabinoid exposure effects on natural reward seeking and learning in rats. Psychopharmacology (Berl) 235:121-134. https://doi.org/10.1007/s00213-017-4749-8

Schomacher M, Müller HD, Sommer C, Schwab S, Schäbitz WR (2008) Endocannabinoids mediate neuroprotection after transient focal cerebral ischemia. Brain Res 1240:213-220. https://doi.org/10.1016/j.brainres.2008.09.019

Scuderi C, Bronzuoli MR, Facchinetti R, Pace L, Ferraro L, Broad KD, Serviddio G, Bellanti F, Palombelli G, Carpinelli G, Canese R, Gaetani S, Steardo L Jr, Steardo L, Cassano T (2018) Ultramicronized palmitoylethanolamide rescues learning and memory impairments in a triple transgenic mouse model of Alzheimer's disease by exerting anti-inflammatory and neuroprotective effects. Transl Psychiatry 8:32. https://doi.org/10.1038/s41398-017-0076-4

Scuderi C, Esposito G, Blasio A, Valenza M, Arietti P, Steardo L Jr, Carnuccio R, De Filippis D, Petrosino S, luvone T, Di Marzo V, Steardo L (2011) Palmitoylethanolamide counteracts reactive astrogliosis induced by $\beta$-amyloid peptide. J Cell Mol Med 15:2664-2274. https://doi.org/10.1111/j.1582-4934.2011.01267.x 
Scuderi C, Stecca C, Valenza M, Ratano P, Bronzuoli MR, Bartoli S, Steardo L, Pompili E, Fumagalli

L, Campolongo P, Steardo L (2014) Palmitoylethanolamide controls reactive gliosis and exerts neuroprotective functions in a rat model of Alzheimer's disease. Cell Death Dis 5:e1419. https://doi.org/ 10.1038/cddis.2014.376

Sebetseba KN, Ramdin T, Ballot D (2017) The use of therapeutic hypothermia in neonates with perinatal asphyxia at Charlotte Maxeke Johannesburg academic hospital: a retrospective review. Ther Hypothermia Temp Manag, in press. https://doi.org/10.1089/ther.2017.0040

Sedláčková N, Krajčiová M, Koprdová R, Ujházy E, Brucknerová I, Mach M (2014) Subchronic perinatal asphyxia increased anxiety- and depression-like behaviors in the rat offspring. Neuro Endocrinol Lett 35(Suppl 2):214-220.

Serrano A, Rivera P, Pavon FJ, Decara J, Suárez J, Rodriguez de Fonseca F, Parsons LH (2012) Differential effects of single versus repeated alcohol withdrawal on the expression of endocannabinoid system-related genes in the rat amygdala. Alcohol Clin Exp Res 36:984-394. https://doi.org/10.1111/j.1530-0277.2011.01686.x

Strackx E, Van den Hove DL, Prickaerts J, Zimmermann L, Steinbusch HW, Blanco CE, Gavilanes AW, Vles JS (2010) Fetal asphyctic preconditioning protects against perinatal asphyxia-induced behavioral consequences in adulthood. Behav Brain Res 208:343-351. https://doi.org/10.1016/j.bbr.2009.11.040

Takada SH, Motta-Teixeira LC, Machado-Nils AV, Lee VY, Sampaio CA, Polli RS, Malheiros JM, Takase LF, Kihara AH, Covolan L, Xavier GF, Nogueira MI (2016) Impact of neonatal anoxia on adult rat hippocampal volume, neurogenesis and behavior. Behav Brain Res 296:331-338. https://doi.org/10.1016/j.bbr.2015.08.039

Ueda N, Tsuboi K, Uyama T (2013) Metabolism of endocannabinoids and related Nacylethanolamines: canonical and alternative pathways. FEBS J 280:1874-1894. https://doi.org/10.1111/febs.12152

Xu J, Chavis JA, Racke MK, Drew PD (2006) Peroxisome proliferator-activated receptor-alpha and retinoid $\mathrm{X}$ receptor agonists inhibit inflammatory responses of astrocytes. J Neuroimmunol 176:95105. https://doi.org/10.1016/j.jneuroim.2006.04.019 
Yang LC, Guo H, Zhou H, Suo DQ, Li WJ, Zhou Y, Zhao Y, Yang WS, Jin X (2015) Chronic oleoylethanolamide treatment improves spatial cognitive deficits through enhancing hippocampal neurogenesis after transient focal cerebral ischemia. Biochem Pharmacol 94:270-281. https://doi.org/10.1016/j.bcp.2015.02.012

Zhou Y, Schwartz BI, Giza J, Gross SS, Lee FS, Kreek MJ (2017) Blockade of alcohol escalation and "relapse" drinking by pharmacological FAAH inhibition in male and female C57BL/6J mice. Psychopharmacology (Berl) 234:2955-2970. https://doi.org/10.1007/s00213-017-4691-9

Zhou Y, Yang L, Ma A, Zhang X, Li W, Yang W, Chen C, Jin X (2012) Orally administered oleoylethanolamide protects mice from focal cerebral ischemic injury by activating peroxisome proliferator-activated receptor

$\alpha$. Neuropharmacology 63:242-249. https://doi.org/10.1016/j.neuropharm.2012.03.008

Zhu H, Qiao L, Sun Y, Yin L, Huang L, Li J, Jiang L (2018) Basic fibroblast growth factor enhances cell proliferation in the dentate gyrus of neonatal rats following hypoxic-ischemic brain damage. Neurosci Lett, in press. https://doi.org/10.1016/j.neulet.2018.01.046 


\section{Figures legends}

Figure 1. Exploratory activity and anxiety-related behaviors in the EPM test. a) Distance covered, b) Closed arm entries, c) Percentage of open arms entries, d) Percentage of time in open arms. Locomotor activity was reduced in Al groups. No differences in anxiety-related behaviors were observed between groups. Sham-Veh, Sham-O2, Sham-O10, Sham-P2, Sham-P10: sham operated rats treated with vehicle, OEA $2 \mathrm{mg} / \mathrm{kg}$, OEA $10 \mathrm{mg} / \mathrm{kg}$, PEA $2 \mathrm{mg} / \mathrm{kg}$, PEA $10 \mathrm{mg} / \mathrm{kg}$, respectively. AlVeh, Al-O2, Al-O10, AI-P2, AI-P10: anoxic-ischemic rats treated with vehicle, OEA 2 mg/kg, OEA 10 $\mathrm{mg} / \mathrm{kg}$, PEA $2 \mathrm{mg} / \mathrm{kg}$, PEA $10 \mathrm{mg} / \mathrm{kg}$, respectively. Symbols and lines depict the mean \pm SEM of 7-10 rats/group. ${ }^{* * *} p<0.01$.

Figure 2. Exploratory activity and anxiety-related behaviors in the OF test. a) Distance covered, b) Number of rears, c) Entries into the center, d) Time in central area. Locomotor activity was reduced in Al groups during their first five minutes of exposition to OF. No differences in anxiety-related behaviors were observed between groups. Sham-Veh, Sham-O2, Sham-O10, Sham-P2, Sham-P10: sham operated rats treated with vehicle, OEA $2 \mathrm{mg} / \mathrm{kg}$, OEA $10 \mathrm{mg} / \mathrm{kg}$, PEA $2 \mathrm{mg} / \mathrm{kg}$, PEA $10 \mathrm{mg} / \mathrm{kg}$, respectively. Al-Veh, Al-O2, Al-O10, Al-P2, Al-P10: anoxic-ischemic rats treated with vehicle, OEA 2 $\mathrm{mg} / \mathrm{kg}$, OEA $10 \mathrm{mg} / \mathrm{kg}$, PEA $2 \mathrm{mg} / \mathrm{kg}$, PEA $10 \mathrm{mg} / \mathrm{kg}$, respectively. Symbols and lines depict the mean

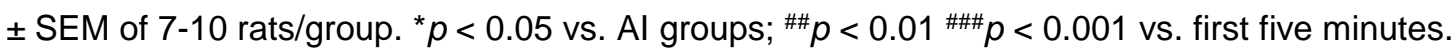

Figure 3. Palmitoylethanolamide treatment prevents recognition memory impairment associated to neonatal anoxia-ischemia. a) Discrimination index (d1) and b) discrimination ratio (d2). One sample t-tests: ${ }^{* * *} p<0.001,{ }^{* *} p<0.01,{ }^{*} p<0.05$ vs. $\mathrm{d} 1$ and $\mathrm{d} 2$ values expected when both objects (familiar and novel) are explored the same amount of time (0 in both cases). Sham-Veh, Sham-O2, Sham-O10, Sham-P2, Sham-P10: sham operated rats treated with vehicle, OEA $2 \mathrm{mg} / \mathrm{kg}$, OEA $10 \mathrm{mg} / \mathrm{kg}$, PEA 2 mg/kg, PEA $10 \mathrm{mg} / \mathrm{kg}$, respectively. Al-Veh, Al-O2, Al-O10, Al-P2, AI-P10: anoxic-ischemic rats treated with vehicle, OEA $2 \mathrm{mg} / \mathrm{kg}$, OEA $10 \mathrm{mg} / \mathrm{kg}$, PEA $2 \mathrm{mg} / \mathrm{kg}$, PEA $10 \mathrm{mg} / \mathrm{kg}$, respectively. Bars depict the mean \pm SEM of 7-10 rats/group.

Figure 4. Spatial learning in the MWM. a) Latency to platform, b) Distance to platform, c) Swim speed. Latency, distance and swim speed decreased similarly across days of training, indicating that all groups acquired the task at the same rate across days of training. Sham-Veh, Sham-O2, ShamO10, Sham-P2, Sham-P10: sham operated rats treated with vehicle, OEA $2 \mathrm{mg} / \mathrm{kg}$, OEA $10 \mathrm{mg} / \mathrm{kg}$, 
PEA 2 mg/kg, PEA 10 mg/kg, respectively. Al-Veh, Al-O2, Al-O10, AI-P2, AI-P10: anoxic-ischemic

rats treated with vehicle, OEA $2 \mathrm{mg} / \mathrm{kg}$, OEA $10 \mathrm{mg} / \mathrm{kg}$, PEA $2 \mathrm{mg} / \mathrm{kg}$, PEA $10 \mathrm{mg} / \mathrm{kg}$, respectively. Symbols and lines depict the mean \pm SEM of 7-10 rats/group.

Figure 5. Spatial reference memory deficit induced by neonatal anoxia-ischemia is prevented by palmitoylethanolamide treatment. a) Percentage of time spent in the target quadrant during the probe trial. ${ }^{* * *} p<0.001,{ }^{* *} p<0.01$ vs. percentage of time expected by chance ( $25 \%$, dashed line). b) Circular area crossing during the probe trial. ${ }^{*} p<0.05,{ }^{*} p<0.01$ vs. sham groups and AI-P10 group. Bars depict the mean \pm SEM of 7-10 rats/group. c) Contingency plots. Sham-Veh, Sham-O2, ShamO10, Sham-P2, Sham-P10: sham operated rats treated with vehicle, OEA $2 \mathrm{mg} / \mathrm{kg}$, OEA $10 \mathrm{mg} / \mathrm{kg}$, PEA 2 mg/kg, PEA 10 mg/kg, respectively. Al-Veh, Al-O2, Al-O10, AI-P2, AI-P10: anoxic-ischemic rats treated with vehicle, OEA $2 \mathrm{mg} / \mathrm{kg}$, OEA $10 \mathrm{mg} / \mathrm{kg}$, PEA $2 \mathrm{mg} / \mathrm{kg}$, PEA $10 \mathrm{mg} / \mathrm{kg}$, respectively.

Figure 6. Immunohistochemical expression of lba-1 in the hippocampus. a) Representative photomicrographs of Iba-1 immunostaining in the hippocampus. Scale bars: $15 \mu \mathrm{m}$. (Photomicrographs of sham groups treated with OEA (2 and $10 \mathrm{mg} / \mathrm{kg}$ ) and PEA (2 and $10 \mathrm{mg} / \mathrm{kg}$ ) can be found in Fig. S3). b-d) Quantification of Iba-1 positive cells across layers of the hippocampus (CA1, CA3 and DG). Bars depict mean \pm SEM of 4-7 sections/rat from groups of 4-5 rats. Sham-Veh, Sham-O2, Sham-O10, Sham-P2, Sham-P10: sham operated rats treated with vehicle, OEA $2 \mathrm{mg} / \mathrm{kg}$, OEA $10 \mathrm{mg} / \mathrm{kg}$, PEA 2 mg/kg, PEA $10 \mathrm{mg} / \mathrm{kg}$, respectively; Al-Veh, Al-O2, Al-O10, Al-P2, AI-P10: anoxic-ischemic rats treated with vehicle, OEA 2 mg/kg, OEA $10 \mathrm{mg} / \mathrm{kg}$, PEA 2 mg/kg, PEA $10 \mathrm{mg} / \mathrm{kg}$, respectively. SO: Stratum oriens; SP: Stratum pyramidale; SR: Stratum radiatum; SL-M: stratum lacunosum molecular; ml: molecular cell layer; gcl: granular cell layer; pcl: polymorphic cell layer. ${ }^{*} p<$ $0.05 ;{ }^{* *} p<0.01$ and ${ }^{* * *} p<0.001$ vs. sham-operated groups.

Figure 7. Immunohistochemical expression of GFAP in the hippocampus. a) Representative photomicrographs of GFAP immunostaining in the hippocampus. Scale bars: $15 \mu \mathrm{m}$. (Photomicrographs of sham groups treated with OEA (2 and $10 \mathrm{mg} / \mathrm{kg}$ ) and PEA (2 and $10 \mathrm{mg} / \mathrm{kg}$ ) can be found in Fig. S4). b-d) Quantification of GFAP positive cells across layers of the hippocampus (CA1, CA3 and DG). Bars depict mean \pm SEM of 4-7 sections/rat from groups of 4-5 rats. Sham-Veh, Sham-O2, Sham-O10, Sham-P2, Sham-P10: sham operated rats treated with vehicle, OEA $2 \mathrm{mg} / \mathrm{kg}$, OEA 10 mg/kg, PEA 2 mg/kg, PEA 10 mg/kg, respectively; Al-Veh, Al-O2, Al-O10, Al-P2, AI-P10: 
anoxic-ischemic rats treated with vehicle, OEA $2 \mathrm{mg} / \mathrm{kg}$, OEA $10 \mathrm{mg} / \mathrm{kg}$, PEA $2 \mathrm{mg} / \mathrm{kg}$, PEA $10 \mathrm{mg} / \mathrm{kg}$, respectively. SO: Stratum oriens; SP: Stratum pyramidale; SR: Stratum radiatum; SL-M: stratum lacunosum molecular; ml: molecular cell layer; gcl: granular cell layer; pcl: polymorphic cell layer. ${ }^{*} p<$ $0.05 ;{ }^{* *} p<0.01$ and ${ }^{* * *} p<0.001$ vs. sham-operated groups; ${ }^{\#} p<0.05$ vs. Al-P10 group; ${ }^{\$} p<0.05$ vs. Sham-Veh group.

Figure 8. Immunohistochemical expression of PPARa in the hippocampus. a) Representative photomicrographs of PPARa immunostaining in the hippocampus. Scale bars: $15 \mu \mathrm{m}$. (Photomicrographs of sham groups treated with OEA (2 and $10 \mathrm{mg} / \mathrm{kg}$ ) and PEA (2 and $10 \mathrm{mg} / \mathrm{kg}$ ) can be found in Fig. S5). b-d) Quantification of PPARa positive cells across layers of the hippocampus (CA1, CA3 and DG). Bars depict mean \pm SEM of 4-7 sections/rat from groups of 4-5 rats. Sham-Veh, Sham-O2, Sham-O10, Sham-P2, Sham-P10: sham operated rats treated with vehicle, OEA 2 mg/kg, OEA 10 mg/kg, PEA 2 mg/kg, PEA 10 mg/kg, respectively; Al-Veh, AI-O2, AIO10, Al-P2, Al-P10: anoxic-ischemic rats treated with vehicle, OEA 2 mg/kg, OEA 10 mg/kg, PEA 2 $\mathrm{mg} / \mathrm{kg}$, PEA $10 \mathrm{mg} / \mathrm{kg}$, respectively. SO: Stratum oriens; SP: Stratum pyramidale; SR: Stratum radiatum; SL-M: stratum lacunosum molecular; ml: molecular cell layer; gcl: granular cell layer; pcl: polymorphic cell layer. ${ }^{* *} p<0.01$ and ${ }^{* *} p<0.001$. 